\title{
Concepción de ser humano detrás de la Quinta Disciplina
}

\author{
Suárez Litvin, Roldan Tomasz*
}

\section{Resumen}

El presente ensayo expone el modo de ser de un ser humano promovido por la Quinta Disciplina de Peter Senge. Luego de un breve resumen de sus principales postulados, se destaca el modo como los mismos apuntan hacia una forma de humanidad y de relación entre el ámbito individual y el organizacional inconsistente con el esquema de pensamiento social moderno. Seguidamente se muestra que esta concepción no-moderna de ser humano guarda ciertas semejanzas con aquella propia de la cultura griega antigua, tal como ésta se expresa en el pensamiento aristotélico. En oposición a esta primera hipótesis interpretativa se procede a articular una segunda, basada en la reflexión heideggeriana acerca de la tecnología. Según esta segunda interpretación, la concepción sengiana de ser humano no constituye más que una muy poderosa reducción de los seres humanos a meros dispositivos al servicio de las organizaciones. Finalmente, se propone un posible camino de debate entre ambas hipótesis interpretativas.

Palabras clave: Quinta disciplina, modernidad, antigüedad, concepción de ser humano

\section{Concept of the Human Being behind the Fifth Discipline}

\section{Abstract}

This article presents an inquiry into the concept of a human being promoted by Peter Senge's Fifth Discipline. After a brief summary of its basic principles, the study shows how they point to a type of humanity and a relationship between individual and organizational domains that is inconsistent with modern social thought. Moreover, it shows that this non-modern concept of a human being has certain similarities to the concept belonging to ancient Greek culture, as expressed in Aristotle's thought. In contrast to this first interpretive hypothesis, a second is articulated based on Heidegger's work concerning modern technology. According to this second interpretation, Senge's concept of a human being is nothing more than a powerful reduction of human beings to mere de-

\section{Recibido: 08-05-10. Aceptado: 10-11-10}

Profesor del Centro de Investigaciones en Sistemología Interpretativa. Universidad de Los Andes. Mérida, Venezuela. e-mail: roldansu@ula.ve. 
vices in the service of organizations. Finally, a possible path for debate between the two interpretive hypotheses is envisaged.

Key words: Fifth discipline, modernity, antiquity, concept of a human being.

\section{Introducción}

Como observa Fuenmayor (1995:32), la mayor parte de la literatura científica dedicada a las tecnologías o métodos gerenciales tiende a enfocar a éstos bajo una óptica en la que el interés central consiste en examinar hasta qué punto y bajo qué condiciones ellos sirven o no como herramientas eficientes y efectivas para alcanzar determinados objetivos organizacionales. En el presente trabajo quisiéramos asumir una óptica distinta, quisiéramos preguntarnos, no por el grado de idoneidad que tales tecnologías tienen como herramientas, sino por los supuestos axiológicos y antropológicos que se hallan implícitos -y por ende ocultos- en ellas. El examen de tales supuestos resulta importante para entender cuál es el cambio de fondo que una determinada tecnología gerencial pretende operar de manera soterrada en la cultura organizacional, más allá de los objetivos explícitamente declarados por sus creadores.

La pretensión de desocultar los ya señalados supuestos implícitos parte de la convicción de que ninguna tecnología es axiológicamente neutra -y mucho menos puede serlo aquella tecnología que busca directamente intervenir y transformar realidades humanas. Como muestra Habermas (1972, 1973), la ilusión de neutralidad de la tecnología es producto de una desvinculación que se dio históricamente en la Modernidad entre la "razón práctica" (dedicada a elegir fines y valores) y la "razón instrumental" (dedicada a elegir medios para alcanzar fines). Tal desvinculación dio pie a la constitución de una racionalidad instrumental "pura", "neutra", dedicada al diseño de tecnologías pretendidamente no vinculadas con ninguna concepción particular. Sin embargo, como muestra el trabajo del propio Habermas (y, en general, el de la Escuela de Frankfurt), así como también el de pensadores como Foucault $(1966,1975)$, Heidegger $(1954,1955) \mathrm{y}$, mucho antes que ellos, Nietzsche (1998), las actividades científicas y técnicas, siendo hechos culturales con sentido dentro de una sociedad, no pueden estar aisladas del conjunto total de creencias, valores y costumbres que conforman la cosmovisión de la misma.

La tecnología gerencial en la que nos enfocaremos en el presente trabajo será la Quinta Disciplina de Peter Senge. Esta tecnología resulta de interés para nuestra temática debido a que explícitamente declara estar comprometida con un pensamiento sistémico acerca de la realidad. El pensamiento de sistemas, según señalan algunos de sus principales exponentes -tales como Bertalanffy (1968), Churchman (1979), Ackoff (1974), Checkland, (1981)- pretende ser un enfoque revolucionario, esencialmente opuesto al pensamiento reduccionista y al modo de vida asociado a éste. Otros, como Fuenmayor y López-Garay (1991), van aún más allá y entienden que la tarea 
fundamental del enfoque de sistemas es la crítica de los sistemas de poder dominantes, guiada por un interés emancipatorio. Parece claro, entonces, que el pensamiento de sistemas trae consigo un compromiso axiológico explícito. Sería de esperar, entonces, que dicho compromiso estuviese de algún modo encarnado en los postulados teóricos y prácticos de la Quinta Disciplina.

El camino que seguiremos en nuestra exploración será el de ir develando, a partir del nivel más explícito del discurso de Senge, sucesivas capas conceptuales, progresivamente más profundas e invisibles. Durante este proceso nos apoyaremos metodológicamente en el uso de varios "contextos interpretativos" -en el sentido en que estos son entendidos por Fuenmayor (1991) en el marco de la sistemología interpretativa. Tales contextos representarán tres concepciones axiológicas y antropológicas contrastantes, correspondientes típico-idealmente a la Modernidad, a la Antigüedad y a la época del Encuadre. En concordancia con el método sistémico-interpretativo, luego de alcanzar un "entendimiento interpretativo" o "interpretación temática" a partir de los ya señalados contextos, procederemos a la fase de "comprensión" de los puntos de vista en juego por medio de la presentación de un posible camino de debate entre las distintas posibilidades interpretativas.

\section{Primera capa: breve recuento de La Quinta Disciplina}

El propósito declarado de la Quinta Disciplina es ofrecer ciertas herramientas básicas que permitan la construcción de una "organización inteligente". Una organización inteligente es un ente colectivo en continuo proceso de aprendizaje -entendiendo por "aprendizaje" el aumento de la capacidad o aptitud para crear con efectividad ciertos resultados deseados.

El corazón de la organización inteligente, es el Pensamiento Sistémico (la "quinta disciplina", como la llama Senge). El pensamiento sistémico tiene por propósito permitir entender el funcionamiento de sistemas de gran complejidad y extensión. En lugar de ver una realidad fragmentada, compuesta de hechos aislados, el pensamiento sistémico invita a ver y modelar la realidad en términos de redes de procesos que se extienden considerablemente en tiempo y espacio, y a apreciar nuestra propia participación en muchos de ellos. Es, precisamente, nuestra participación inconsciente en los procesos que se dan a nuestro alrededor, lo que exige una continua revisión de los presupuestos invisibles, o Modelos Mentales, sobre los que estamos parados. EI pensamiento sistémico y la disciplina de los modelos mentales permiten, entonces, adquirir una mayor conciencia acerca del funcionamiento de la realidad, tanto interna como externa a la organización.

Sin embargo, esta conciencia expandida acerca de la realidad no lo es todo. La organización inteligente se propone actuar efectivamente en esa realidad, buscando en ella puntos de "alto apalancamiento" para dirigirla hacia ciertos objetivos. Hace falta, entonces, que la organización desarrolle la capacidad de actuar como un solo ser altamente coordinado. Esta coordinación es lograda mediante la práctica de dos disciplinas: la Vi- 
sión Compartida y el Aprendizaje en Equipo. La visión compartida tiene por propósito el mantenimiento de una aspiración colectiva unitaria en todos los miembros de la organización, una fuerza que le brinde sentido, dirección y unidad a cada actividad de cada miembro de la organización. El aprendizaje en equipo pretende desarrollar la aptitud para coordinar acciones individuales de manera de lograr un perfecto "alineamiento" -en dirección de la visión compartida- de los esfuerzos de cada quien.

Finalmente, todo lo anterior requiere de un cambio fundamental de actitud de los miembros de la organización. La nueva actitud que se requiere para lograr construir una organización inteligente es la del Dominio Personal. El dominio personal define la esencia del "pensador sistémico": una persona comprometida con la búsqueda de la verdad sobre la realidad, y dispuesta a encontrar en ella los puntos de alto apalancamiento que le permitirán moldearla de acuerdo con sus fines. El dominio personal, según Senge (1993:179), es un modo de ser que define "el espíritu de la organización inteligente".

\section{Segunda capa: la importancia del dominio personal}

Notemos que, mientras que las primeras cuatro disciplinas constituyen herramientas orientadas hacia el desarrollo de habilidades que permitan una mayor coordinación y efectividad de la organización, la disciplina del Dominio Personal pretende algo distinto: fomentar un "espíritu" o "modo de ser" en los miembros de la organización: "El dominio personal trasciende la competencia y las habilidades, aunque se basa en ellas", dice Senge (1993:181) al respecto. En efecto, ese modo de ser aparece bajo dos formas en el discurso de Senge:

a) Como medio indispensable para la construcción de una "organización inteligente". Según Senge (1993:179), "las organizaciones sólo aprenden a través de individuos que aprenden". La intencionalidad propia de toda organización inteligente sólo puede provenir de una reunión coherente de ese mismo tipo de intencionalidades en cada uno de sus miembros. En efecto, la intencionalidad fundamental que manifiesta una organización inteligente es, como ya hemos visto, la del compromiso con el "aprendizaje". Este compromiso, según Senge (1993:11), se expresa en un afán por expandir "continuamente su aptitud para crear los resultados que desea". El dominio personal brinda exactamente lo mismo, sólo que a nivel individual: De acuerdo con Senge (1993:181), "la gente con alto nivel de dominio personal expande continuamente su aptitud para crear los resultados que buscan en la vida. De su búsqueda de aprendizaje continuo surge el espíritu de la organización inteligente". Es por eso que para Senge (1993:182) "las organizaciones inteligentes no son posibles a menos que en todos los niveles haya personas dispuestas a practicar esa forma de aprendizaje".

b) Como un fin en sí mismo, en la medida en que constituye una aspiración intrínseca a la naturaleza humana. 
Senge (1993:12) afirma claramente que "las organizaciones inteligentes son posibles porque aprender no sólo forma parte de nuestra naturaleza sino que amamos aprender". Es propio del ser humano el que su autorrealización radique en el aumento de la capacidad para lograr -de modo cada vez más eficiente y efectivosus fines y propósitos. Incluso, según Senge (1993:190), "la dicha puede ser resultado de vivir en coherencia con nuestro propósito". Obsérvese que, siendo así, las organizaciones inteligentes no sólo serían útiles, sino que serían éticamente deseables, ya que constituyen el escenario más propicio para el pleno desarrollo de la naturaleza humana. Es en la organización inteligente donde, según Senge (1993:11), "la aspiración colectiva queda en libertad, y donde la gente continuamente aprende a aprender en conjunto". Se trata, pues, de construir un modelo organizacional que no sólo sea más eficiente, sino que, de acuerdo con Senge (1993:180), sea "más congruente con la naturaleza humana".

\section{Tercera capa: la nueva relación individuo- organización}

Ahora bien, ¿cómo es posible alcanzar, simultáneamente, la eficiencia organizacional y la autorrealización de los actores organizacionales como seres humanos? En nuestra sociedad usualmente estos dos objetivos son considerados como opuestos y contradictorios. Tendemos a pensar que las organizacio- nes buscan obtener de sus trabajadores el máximo trabajo y esfuerzo posibles a cambio de la menor remuneración posible. Los trabajadores, en cambio, buscan lo contrario: obtener la máxima remuneración posible a cambio de la menor cantidad de trabajo y esfuerzo posible. Bajo esta óptica, los intereses de cada uno y los fines que persiguen son claramente opuestos. Sin embargo, los supuestos acerca de la relación individuo-organización que se hallan implícitos en la Quinta Disciplina parecen oponerse a la concepción tradicional de dicha relación. Veamos con más detalle cuál es la base conceptual que sustenta, en el marco de la Quinta Disciplina, esta nueva relación -aparentemente no-conflictiva- entre individuo y organización.

La premisa fundamental del dominio personal es que el individuo se realiza como ser humano desarrollando las aptitudes para lograr los fines que desea. Esto lo impulsa a desarrollar la capacidad para ganar una "visión sistémica" de la realidad, la cual le muestra el carácter interconectado de todos los eventos; en particular, el carácter interconectado de las acciones humanas. Sobre la base de dicha visión el ser humano comprende la necesidad de unirse a otros -organizarse- para ejercer un control más efectivo sobre la realidad. Por otra parte, el afán por obtener una visión global de la realidad hace que el individuo quiera proponerse fines globales, es decir, fines que tengan importancia no sólo para él, sino también para los demás. Surge, así, según Senge (1993:356), "el deseo de crear algo nuevo, algo que tenga valor y significado para la gente". Como vemos, el afán por participar en organizaciones, persi- 
guiendo propósitos compartidos, es una consecuencia directa de la tesis antropológica inicial acerca de cuáles son los fines esenciales que cada individuo tiene. Es así como la brecha entre fines individuales y fines organizacionales se cierra.

En términos de Senge (1993:13), la Quinta Disciplina cambia la visión "instrumental" del trabajo por una visión "sagrada", que busca "los beneficios intrínsecos del trabajo" -es decir, donde el trabajo no es un simple medio, sino que es un fin en sí mismo. La nueva relación individuo-organización ya no se daría, entonces, bajo la forma de un "contrato" (donde el trabajo es vendido para obtener un bien externo a éste), sino de un "pacto". Al respecto Senge (1993:186) dice: "Una relación completa requiere de un pacto... una relación de pacto descansa sobre un compromiso compartido con ideas, problemas, valores, metas y procesos de administración... Los pactos reflejan unidad, gracia y equilibrio. Expresan la índole sagrada de las relaciones". En la relación de "pacto", ni la organización es un simple medio para alcanzar fines individuales, ni los individuos son simples medios para alcanzar fines organizacionales. Ambos tipos de fines se unifican en una única "visión compartida". Por eso la relación social dentro de una organización inteligente tiene que estar basada no en la competencia sino en la solidaridad y mutua ayuda en la persecución de un bien común. Más aún, las fronteras ontológicas entre lo individual y lo organizacional tienden a desdibujarse: EI individuo difícilmente puede ser sin la organización porque el espacio organizacional, sus metas y propósitos, su "visión compartida", en gran medida definen su identidad individual. En efecto, la organización inteligente, de acuerdo con Senge (1993:190), le brinda al ser humano "la verdadera alegría de la vida, el ser usado para un propósito que él mismo reconoce como poderoso". Cuando el individuo alcanza esta situación, su "tarea ya no está separada del yo... sino que él se identifica tanto con la tarea que ya no se puede definir el verdadero yo $\sin$ incluir esta tarea", según Senge (1993:264).

Es aquí, precisamente, donde surge con fuerza la pregunta por la concepción de ser humano que la Quinta Disciplina parece promover desde el fondo de sus propuestas. Un ser humano ontológicamente dependiente de -y definido porsu entorno social es un ser humano concebido en términos incompatibles con los cánones antropológicos establecidos por la Modernidad. ¿Qué clase de cambio está anunciando la Quinta Disciplina?

\section{Cuarta capa: el carácter no-moderno del nuevo modo de ser un ser humano}

¿Por qué la organización del trabajo productivo moderno se ha entendido usualmente en términos de un conflicto entre individuo y organización? Como bien observa Senge, las organizaciones tradicionales, basadas en el "contrato", funcionan bajo la idea de un intercambio de bienes llevado a cabo con el propósito de que cada una de las partes (organización por un lado y trabajador por el otro) pueda alcanzar sus fines particulares. Es decir, se asume de antemano que los propósitos de la organización no coinciden con los propósitos personales de sus miembros. Pero, ¿por qué? ¿De dónde 
proviene este modo de entender la relación individuo-organización? La pista la proporciona la misma noción de "contrato". Si rastreamos históricamente el momento en que la noción de "contrato" se instala en nuestro modo de concebir lo social y lo político, pronto descubrimos que es la Modernidad la que inaugura esta tendencia. En efecto, es el pensamiento filosófico moderno el que postula, como fundamento de lo social, un contrato: el Contrato Social. Veamos esto con mayor detenimiento.

La reflexión filosófica moderna en torno a lo político gira, en todas sus variantes, en torno al problema del conflicto social. El conflicto social aparece bajo distintas modalidades. Por un lado es postulado como una realidad que dio, históricamente, origen al Estado -como ocurre, por ejemplo, en Hobbes (1980) y su "guerra de todos contra todos". Por otra parte es pensado como una posibilidad continuamente latente en el espacio social-este es el caso de Kant (1987) con su tema de la "insociable sociabilidad" del hombre. Lo importante, sin embargo, es que la razón de ser del Estado, y, en general, de toda forma de organización social, es postulada siempre a partir de la necesidad de contener el conflicto social, especialmente en su modalidad violenta. El Estado aparece como aquel ente que es capaz de imponer un orden que limite la arbitrariedad de sus súbditos y garantice la paz. La explicación o justificación de la existencia del Estado se da mediante la idea de un acuerdo entre seres humanos que se proponen eliminar o minimizar la incertidumbre ante las acciones del otro. Ese acuerdo no es otra cosa que el Contrato Social. El sentido de toda organiza- ción social moderna se nutre y se enraíza, de esta manera, en la presencia (real o posible) del conflicto social.

Ahora bien; ¿qué noción de "ser humano" fundamenta esta relación entre el conflicto social y la organización social en el pensamiento moderno? Notemos que la organización social es inaugurada y sostenida mediante un acto consciente de voluntad por parte de un conjunto de individuos. Esto implica que los individuos son pensados como preexistentes como tales a la sociedad. Como individuos se asocian unos con otros, mediante un contrato, para conformar una organización social. La aparición de toda organización social se origina en decisiones individuales. ¿Cual es el afán que guía al ser humano en esta decisión? Los individuos pueden estar interesados en un orden social pacífico por distintos motivos. Hobbes postula que estos motivos son absolutamente egoístas: el cálculo del beneficio propio obliga a los hombres a someterse a un poder soberano y limitar su libertad a cambio de un espacio individual de no-interferencia en el que puedan hacer lo que les plazca. Kant, en cambio, postula un propósito meramente moral: el que impone el deber de crear las condiciones de respeto a los derechos del hombre para que, de esta manera, pueda florecer la perfección moral en cada quien. En ambos casos se supone que la organización social es instituida voluntariamente como un medio para contener el conflicto social y para crear ciertas condiciones en las que los seres humanos puedan realizar sus propósitos individuales. Nótese que aquí el conflicto es la base de la necesidad de organizarse. 
Por lo dicho hasta este momento podemos concluir lo siguiente: En primer lugar, en la concepción filosófica moderna el ser humano ya es como tal -hace uso de su razón, tiene voluntad, se plantea propósitos- antes de entrar en cualquier relación social: el orden social es constituido mediante una decisión. En segundo lugar, lo que la filosofía política moderna llama el "estado natural del hombre", es decir, su estado pre-organizacional, es un estado potencialmente conflictivo porque los hombres pueden y suelen tener propósitos conflictivos. Finalmente, la organización social es un medio para disminuir la incertidumbre entre los individuos y asegurar, así, las condiciones necesarias para la realización de sus propósitos extra-organizacionales.

Ahora bien, la entrada del individuo en una organización social implica, evidentemente, el sometimiento de éste al orden de la misma. Dentro de ese orden el individuo ha de cumplir con una serie de obligaciones que definen su papel o rol social dentro de la organización. Obsérvese que el rol del individuo dentro de la organización le es siempre accidental, es decir, no es definitorio de su ser o su identidad. Obsérvese, también, que el individuo acepta someterse a las exigencias de cierto rol porque, como dijimos, pretende lograr, mediante esto, ciertos propósitos externos a ese rol y anteriores a él. El hombre moderno, entonces, tiene que vivir continuamente una tensión entre sus propósitos como hombre y los propósitos que le son impuestos por el rol que desempeña.

Desde esta perspectiva resulta inmediatamente comprensible el modo usual de concebir la relación individuo-organización. La actividad que desarrolla el individuo en su organización nunca puede ser, para él, un bien en sí mismo (un "beneficio intrínseco", en palabras de Senge), siempre es sólo un medio. En el caso hobbesiano, es un medio para tener acceso a ciertos bienes y fines particulares del individuo que le proporcionan bienestar y felicidad. En el caso kantiano, es un medio para asegurar unas condiciones de vida que fomenten el florecimiento de la perfección moral. La felicidad y/o la autorrealización del hombre se da siempre fuera del ámbito organizacional. Lo organizacional es sólo un medio para el logro de la plenitud humana, como sea que se quiera concebir esta.

A la luz de estas ideas modernas resulta extraña y ajena la visión del hombre (como esencia y proyecto) que presenta la Quinta Disciplina. El hombre aquí realiza su dicha y felicidad directamente mediante su desempeño eficiente en la organización. La participación en la organización deja de ser sólo una condición de posibilidad para el logro de su plenitud; se torna, por sí misma, plenitud. Al coincidir la "visión personal" con la "visión compartida" (organizacional) desaparece la tensión en la que vivía el hombre moderno. Pero esto, en el fondo, implica la desaparición del hombre moderno como tal: Mientras la identidad del hombre moderno es pre-organizacional, la identidad del hombre sengiano se construye en torno a la organización en la que vive. El hombre sengiano se funde con el rol que desempeña en la organización. Sus intereses particulares no son extra-organizacionales, sino que quedan acogidos por la visión compartida. Y 
la plenitud humana se realiza en la persecución del fin organizacional.

Ahora bien, la disonancia entre las ideas expresadas en la Quinta Disciplina y ciertos presupuestos básicos de orden axiológico y antropológico propios de la Modernidad hacen surgir la pregunta de cuál es el origen histórico de esas ideas y en qué medida ellas anuncian un regreso al pasado $o$ un avance hacia el futuro con respecto a nuestro momento histórico presente. Como veremos a continuación, las ideas no-modernas que encontramos implícitas en la Quinta Disciplina guardan cierto parecido con el modo de concebir lo individual y lo social en la cultura de la antigüedad clásica griega, en particular con el modo propio de la polis griega. ¿Estará desocultando, la Quinta Disciplina, un proceso de retorno a un modo de ser un ser humano y a un modo de convivir con el otro propios de los orígenes de la cultura occidental?

\section{Quinta capa: La hipótesis de la "neo-antigüedad"}

De acuerdo con Maclntyre (1985), la vida en la polis griega clásica gira en torno a una ética que pretende posibilitarle al ser humano vivir su vida como una "buena vida". Esta ética, según el recuento que hace de ella Aristóteles (2000), puede ser estructurada en torno a tres nociones centrales:

a) El ser humano como-suele-ser: En su modo de ser habitual, el ser humano es una especie de materia prima, un manojo de pasiones en bruto carentes de foco y unidad. Bajo esta condición desordenada el ser humano es víctima de deseos contradicto- rios que lo mantienen desgarrado, intranquilo e infeliz. Sin embargo, ese material tosco inicial posee algo en su naturaleza -la razón (logos) - que lo predestina a convertirse en algo de otro tenor. Ese otro estado posible, descubierto por la razón, es el telos del ser humano, el fin último de la existencia del hombre, el bien supremo asociado a su naturaleza.

b) El ser humano como-podría-ser-si -realizara-su-naturaleza-esencial: El telos, fin o bien supremo de la vida humana se expresa en la idea de eudaimonía, felicidad plena. Eudaimonía es el estado que alcanza el ser humano al vivir una "buena vida" o una "vida excelente". La vida excelente, por su parte, es aquella en la que cumplimos del mejor modo posible con cada uno de nuestros roles sociales, y sobre todo, con nuestra función de seres pensantes, racionales, de la cual depende nuestra capacidad de cumplir bien con cualquier rol social. Por ello, aunque la eudaimonía es un estado individual, el mismo sólo es posible en el seno de una sociedad. Sin embargo, más que de una sociedad, se trata de una comunidad reunida en torno al proyecto común de brindar a cada quien la posibilidad de alcanzar la felicidad por medio del excelente desempeño de sus roles en dicha comunidad.

c) Los medios que permiten la transición: La transición de un estado del ser humano al otro se realiza mediante la práctica de las virtudes. Las virtudes son, por una parte, el cincel que transforma la materia bruta de las pasiones y, por la otra, forman parte 
integral del telos. En otras palabras, la práctica de las virtudes es el medio que permite la sintesis final de todas ellas en aquella persona que ha alcanzado la eudaimonía. Adicionalmente, la práctica de las virtudes tiene como objetivo salvaguardar el buen orden social de la polis, ya que la acción virtuosa, al favorecer el buen desempeño de los roles sociales, favorece la armonía de la sociedad.

Ahora bien, ¿qué noción de ser humano y de relación social se hallan implícitas en este tipo de pensamiento? EI hombre antiguo no puede concebir el inicio de la relación con el otro en términos de una decisión basada en fines individuales. La relación social no es pensada como una realidad secundaria con respecto a lo individual, sino como constitutiva de ésta: el individuo alcanza su condición propiamente humana sólo sobre la base de lo social. Más aún, como parte de una comunidad, la identidad del hombre antiguo se define de acuerdo con el rol social dentro del contexto de su comunidad y en relación con los roles de los demás. Lo que cada individuo es y lo que constituye su bien depende de manera radical del papel desempeñado dentro de la comunidad.

Por otra parte, dada esta noción de ser humano, el conflicto no puede, de ninguna manera, ser pensado o vivido como la relación social primaria. Si así fuese, el surgimiento de la humanidad sería totalmente incomprensible -ya que ésta, como hemos visto, nace en el seno de una comunidad. Como postula Aristóteles, la relación de amistad, y no la de mutua desconfianza, tiene que ser la rela- ción fundamental que da origen a la humanidad como tal.

Nótese, entonces, que bajo esta forma de pensamiento no puede haber tensión entre lo que es bueno para la polis y lo que es bueno para cada uno de sus miembros. El bien del individuo se realiza persiguiendo el bien de la polis de la manera en que le corresponde hacerlo de acuerdo con sus roles sociales particulares. El bien de la polis, por otra parte, radica en hacer posible el florecimiento del bien de sus ciudadanos. La perfección de la polis como comunidad implica la perfección de sus ciudadanos como seres humanos y viceversa.

Ahora bien, regresando a nuestra temática principal, parece claro que la organización inteligente de la Quinta Disciplina adquiere un nuevo sentido a la luz de esta perspectiva aristotélica. Podemos observar la coincidencia de toda una serie de elementos entre la organización inteligente y la polis. Veamos algunas de las más evidentes:

a) El Dominio Personal es un modo de ser que, como hemos visto, aparece, por una parte, como medio para lograr una organización inteligente, $y$, por la otra, como un fin en sí mismo propio de la naturaleza esencial del ser humano. La noción de ser humano "virtuoso" o "eudaimónico" posee esas mismas características: es un medio para la construcción de la polis y es un fin en sí mismo propio de la naturaleza humana.

b) El trabajo en la organización es, por tanto, un bien intrínseco y no un mero medio, pues en él se ejercen y desarrollan las disposiciones naturales del hombre. Lo mismo puede afirmarse 
en el caso del esquema aristotélico, donde el desempeño excelente de los roles asignados dentro de la polis constituye el camino hacia la plena autorrealización del individuo.

c) El triple papel que juegan las virtudes en la buena vida puede equipararse al de las disciplinas en la organización inteligente. Las disciplinas son: herramientas de entrenamiento personal, características constitutivas del pensador sistémico y prácticas que contribuyen al mantenimiento de la unidad y la coherencia de la organización.

d) El fundamento de la "buena vida" en la polis es el ejercicio de las capacidades racionales del ser humano con miras a comprender el orden en el cual se inserta, o se debe insertar, la actividad excelente de cada quien. En el caso de la Quinta Disciplina pudiera decirse que ese fundamento es el entrenamiento de la capacidad para comprender sistémicamente la realidad interconectada.

e) El individuo sengiano, al igual que el aristotélico, define su identidad en torno a la pertenencia a su organización: no tiene un "yo" más allá de la tarea que realiza. Su bien individual no se distingue del bien organizacional y su plenitud se da en la constante persecución del fin organizacional compartido. Su "buena vida" consiste en desempeñarse excelentemente en su rol como miembro de la organización. El pensador sistémico con la actitud propia del dominio personal corresponde, en ese sentido, al modelo de "hombre virtuoso" aristotélico.
Estas coincidencias parecen sugerir que nos encontramos a las puertas de una época que abandona la noción moderna de ser humano -desgarrado entre lo individual y lo social- a favor de una concepción que define al individuo dentro del contexto de su comunidad. ¿Estaríamos presenciando una soterrada vuelta al modelo de vida propio de la Antigüedad? Nótese que, si éste fuese el caso, la Quinta Disciplina efectivamente estaría siendo fiel al carácter "emancipador", "revolucionario" que a veces se le asigna al pensamiento de sistemas. Se trataría, en efecto, de una revolución muy profunda; una revolución que estaría atacando las bases mismas de toda una época histórica como lo es la Modernidad. Sin embargo, antes de postular una tesis tan atrevida es necesario que examinemos no sólo las similitudes, sino también las diferencias entre la organización inteligente y la polis antigua. Intentemos, pues, articular una interpretación muy distinta a esta primera hipótesis de la "neo-antigüedad".

\section{Sexta capa: la hipótesis del "encuadre"}

La comparación que hemos realizado entre los modos de ser un ser humano propios de la Antigüedad y de la Quinta Disciplina es de carácter lógico. Esto significa que hemos establecido una correspondencia entre ciertos conceptos: polis-organización inteligente, virtudesdisciplinas, contemplación-aprendizaje, etcétera. Sin embargo, en esta comparación hemos perdido de vista el carácter histórico de ambos contextos. Pregunté- 
monos, entonces: ¿qué situación histórica le da sentido a la aparición de la Quinta Disciplina?

Un primer y muy simple intento de respuesta a esta pregunta podría hacer referencia a la no muy larga historia del desarrollo del área de gerencia y administración. Esta historia -cuyo inicio por lo general se suele ver en la "administración científica" de Taylor (1969)- narra la evolución de una serie de técnicas y métodos de organización de recursos humanos y materiales destinados a la maximización de la eficiencia y la efectividad organizacionales. Dentro de esta narrativa se suele destacar el hecho de que los primeros enfoques gerenciales no tomaban en cuenta los aspectos subjetivos, intangibles de las relaciones humanas, sino que concebian la realidad organizacional de manera mecanicista, como si ésta fuese un sistema determinístico, y como si el trabajador no fuese más que una pieza dentro de la maquinaria organizacional. Bajo esta visión el esfuerzo de las tecnologías gerenciales se concentraba en conseguir los modos más convenientes de distribuir las tareas en el tiempo y en el espacio, bajo el supuesto implícito de que cada trabajador cumpliría con la tarea asignada. La relación del trabajador con su tarea, el grado de satisfacción con su trabajo y, más allá, su "plenitud" o "felicidad", no eran del interés de estas tecnologías, pues dominaba la idea (heredada de las teorías sociales y políticas de la Modernidad) de que estos temas pertenecen al ámbito extra-organizacional, privado del trabajador.

Sin embargo, desde el surgimiento de la escuela de "Relaciones Humanas", en el campo de la gerencia empieza a cobrar auge un interés por el trabajador no simplemente como una pieza de maquinaria sino como un ser humano. Tal interés es doble. Por un lado, empieza a evidenciarse la importancia que tienen para el funcionamiento de la organización ciertos factores sutiles, poco visibles, relacionados con la subjetividad humana (ej.: satisfacción laboral, variedad interpretativa, juegos de poder, conflicto de intereses, etcétera). Por otro lado, eventos como el fin de la Segunda Guerra Mundial, el comienzo de la Guerra Fría y las turbulencias políticas e ideológicas de fines de los años sesenta del siglo pasado contribuyen a la aparición de un discurso "humanista" en el campo de la gerencia, el cual plantea la necesidad de ofrecerle al trabajador condiciones laborales menos opresivas y alienantes que las tradicionales, de tal manera que éste pueda realizarse como ser humano en su trabajo.

El gran problema que aparece entonces ante las tecnologías gerenciales puede condensarse en la siguiente pregunta: ¿cómo maximizar la eficiencia/efectividad organizacional y a la vez asegurar la autorrealización de los trabajadores como seres humanos dentro de la organización? Notemos que la pregunta misma ya está planteada desde una perspectiva en la que predomina el problema de la eficiencia: la necesidad de la eficiencia organizacional no es cuestionada, se mantiene como punto de partida de toda reflexión. En otras palabras, el afán de reunir eficiencia y autorrealización surge a partir del afán de eficiencia. Parece claro que no podría ser de otra forma, pues la pregunta surge, en primera instancia, en 
el campo de las tecnologías gerenciales y no en el campo de la filosofía.

Ahora bien, por las razones expuestas en la sección 5 , el problema anterior no puede tener solución dentro del dominio del pensamiento social y político moderno. La única solución posible es aquella que presenta la Quinta Disciplina: hace falta invocar un modo de ser un ser humano que postule que la plenitud humana consiste en la maximización de la capacidad para actuar con eficiencia y efectividad dentro del ámbito organizacional. Visto de esta manera, el propósito de la Quinta Disciplina sería la creación de un tipo de ser humano conveniente y adecuado al funcionamiento óptimo de las organizaciones. No se trataría, entonces, de revolucionar el presente para emanciparnos de una noción de "ser humano" falsa o limitada y retomar una noción anterior considerada como más completa o verdadera. Se trataría de imponer retóricamente unas ideas acerca del ser humano que, independientemente de su veracidad o falsedad, fuesen útiles para el mundo organizacional. Pero, ¿cómo podemos saber que éste, efectivamente es el caso? ¿Cómo saber si la noción de ser humano implícita en la Quinta Disciplina es sólo retórica conveniente o si surge de un genuino interés por comprender verazmente la condición humana y adaptar la vida organizacional a ella? Por otra parte, ¿cómo saber si el pensamiento aristotélico no es, también, sólo retórica hábil puesta al servicio de la organización social propia de la polis? Antes de abordar estas cuestiones hace falta complementar y enriquecer esta segunda hipótesis que hemos bosquejado en torno a la Quinta Disciplina.
La creación de concepciones antropológicas instrumentalmente útiles para el buen desempeño de las organizaciones adquiere mayor sentido si trascendemos el estrecho contexto de la historia del campo de la gerencia y la administración y consideramos un contexto histórico más amplio, referente al devenir de la Modernidad. Para ello resulta de mucho provecho la reflexión heideggeriana acerca de la tecnología moderna. En efecto, Heidegger $(1954,1955)$ concentró sus esfuerzos en comprender a fondo el peligro del modo de pensar y actuar resultante del devenir histórico de la Modernidad. En su obra intentó mostrar que dicho modo se funda en una relación con el ser en la que todo ente es reducido sistemáticamente a una "cosa-lista-para-ser-usada" (Bestand); es decir, a un simple "dispositivo" al servicio de la voluntad humana. Bajo este "modo tecnológico de revelado", característico de nuestra época actual -llamada por Heidegger "Encuadre" (Gestell)-, la riqueza naturalmente presente en el ser de las cosas se ve dramáticamente reducida, se va desvaneciendo la posibilidad de comprender el mundo más allá de ese mínimo requerido por una racionalidad estrictamente instrumental. Así, nuestra experiencia del mundo y de nosotros mismos tiende a simplificarse en extremo, hasta el punto de que desaparece, paulatinamente, la posibilidad de asombrarse ante lo que las cosas son y de indagar en la verdad de su ser.

Heidegger contrasta este modo tecnológico de revelado, dominante en el presente, con el modo de revelado asociado a la antigua noción griega de "poiesis" -traducida por Heidegger como "traer-aquí-delante" (Hervorbringen). Se- 
gún Heidegger, lo propio de este modo poiético de revelado, dominante en la Grecia Antigua, es que la presencia de las cosas se experimenta como sostenida por un incesante acto de desocultamiento, es decir, de tránsito desde el noser hacia el ser. Bajo esta concepción, las cosas no tienen su existencia garantizada en sí misma, sino que su aparecer y su perdurar en el tiempo se debe a algo distinto a ellas. Aquello a lo cual las cosas deben su ser es lo que las conduce a su destino, lo que las hace llegar-a-ser lo que son. Ese "algo" que es de una naturaleza distinta a cualquier cosa, esa no-cosa que es responsable de todas y cada una de las cosas, es vivida como un misterio esencial en el cual se origina la presencia. Así, para el antiguo hombre griego, el ser de cada cosa se halla envuelto en un misterio abismal que incesantemente apela a su curiosidad y estimula la exploración de la verdad de su ser.

A la luz de estas ideas heideggerianas la posibilidad de que la Quinta Disciplina esté forjando una noción de ser humano útil para el buen funcionamiento de las organizaciones es inmediatamente comprensible en términos de una profundización del proceso de transformación de todos los entes en cosas-listas-paraser-usadas. De hecho, se trataría de una muy poderosa modalidad de reducción del propio ser humano a dicha condición, pues permitiría ocultar su verdadera naturaleza tras la fachada de una preocupación por la realización plena del individuo como ser humano. Por otra parte, el contexto heideggeriano permite comprender también por qué la tesis sengiana acerca de la naturaleza humana no obedecería a una auténtica búsqueda de la verdad: bajo el revelado tecnológico el empobrecimiento del ser, de las cosas, hace que se deprima el afán inquisitivo en torno a lo que ellas son. Esto da paso a un manejo meramente instrumental de las ideas, convirtiéndolas en dispositivos retóricos que disimulan su función utilitaria tras una aparente pretensión de verdad.

\section{Conclusión: el debate entre las dos hipótesis}

Estamos más preparados ahora para retornar a la pregunta de cuál de las dos interpretaciones de la Quinta Disciplina que hemos presentado resulta más adecuada y comprensiva. ¿Es la Quinta Disciplina expresión de un genuino (aunque no del todo consciente) afán por retomar un esquema aristotélico de pensamiento acerca de lo humano o, por el contrario, se trata de un uso meramente instrumental, retórico de ideas aparentemente afines a las de Aristóteles pero no impulsadas por un auténtico interés por acercarse a la verdad acerca de la condición humana? Por otra parte, ¿cómo podemos saber que Aristóteles efectivamente estaba impulsado por tal interés?

Debemos observar, en primer lugar, que el marco heideggeriano pone de manifiesto el hecho de que la búsqueda de la verdad acerca de lo humano requiere de ciertas condiciones de posibilidad. Por una parte, buscar la verdad requiere, en general, de un modo de revelado del ser en el que las cosas se presenten con suficiente riqueza y, a la vez, estén envueltas en suficiente misterio como para incitar al pensamiento a la búsqueda de la verdad. Por otra parte, el tipo de pensamiento acerca de lo humano expresado 
en la obra de Aristóteles requiere de una ontología en la cual el ser de las cosas sea visto como esencialmente dependiente de algo trascendente a ellas. Sólo bajo esta condición puede tener pleno sentido el concebir al ser humano como esencialmente dependiente de $-y$ definido en su identidad por- su contexto social. Como hemos visto, con ayuda de Heidegger, la experiencia griega antigua del ser cumple con ambas condiciones, lo cual hace posible (aunque no seguro) que el trabajo de Aristóteles responda a una auténtica búsqueda de la verdad. Pero, ¿qué ocurre con estas precondiciones ontológicas en el caso de Senge?

Ya hemos visto que el modo de revelado propio del Encuadre es inhóspito a la búsqueda de la verdad. Por ello, si la Quinta Disciplina estuviese movida por un genuino afán de dar cuenta verazmente de la condición humana tendría que postular una ontología distinta a aquella propia del modo tecnológico de revelado. ¿Cuál es, entonces, la concepción ontológica presente en el discurso de Senge?

La respuesta a esta pregunta la encontramos en el modo como Senge entiende el "pensamiento sistémico": esa "quinta disciplina" que constituye para él el punto de partida para una adecuada comprensión de la realidad. En efecto, recordemos que el pensamiento sistémico, tal como lo describe Senge, está interesado en descubrir en la realidad aquellas interrelaciones causales entre los fenómenos que permitan encontrar los puntos de "alto apalancamiento" por medio de los cuales es posible intervenir y controlar dicha realidad con miras al logro de ciertos objetivos preestablecidos. Esto significa que la relación con la realidad, en el marco de esta clase de "pensamiento sistémico", es netamente instrumental y, por ende, totalmente acorde con el modo tecnológico de revelado. No cabría, entonces, según esto, ninguna búsqueda auténtica de la verdad acerca del ser humano en el contexto de la Quinta Disciplina. El ser humano sólo sería de interés aquí en tanto instrumento eficiente para la realización de ciertos fines. Y toda la prédica de Senge acerca de la naturaleza humana, de su llamado esencial a alcanzar fines compartidos en el marco de comunidades organizadas, habría que comprenderla como un intento por tocar ciertas fibras íntimas en los seres humanos (quizás sus puntos de "alto apalancamiento") para hacer de ellos instrumentos útiles a la actividad gerencial.

Todo esto se trasluce de manera más o menos velada en una frase en la que el propio Senge (1993:190) parece negar la posibilidad de dilucidar seriamente el verdadero sentido de la vida humana: "Nadie puede demostrar ni refutar la afirmación de que los seres humanos tienen un propósito. Sería infructuoso iniciar ese debate. Pero como premisa funcional, la idea tiene una gran potencia". Resulta claro que esa "gran potencia" está relacionada con los resultados que pueden obtenerse por efecto de la adopción de dicha "premisa funcional" por parte de todos los miembros de la organización, independientemente de que tal premisa sea verdadera o falsa.

Sin embargo, debemos matizar un poco esta categórica conclusión a la cual hemos arribado a través de nuestro camino inquisitivo. Si bien parece indiscutible el hecho de que la Quinta Disciplina defiende postulados axiológicos y antropo- 
lógicos que no pueden tener sentido en términos de sus propias premisas ontológicas, es necesario dar cabida a la posibilidad de que ello no sea más que expresión de un proceso histórico de transición desde un modo tecnológico de revelado hacia alguna otra experiencia del ser cuyas características aún no están del todo claras. En ese caso sería comprensible que la Quinta Disciplina combinase, de manera lógicamente inconsistente, elementos del modo de revelado anterior con elementos del nuevo modo de revelado. De hecho, aún aceptando que es cierto que el discurso de Senge en torno a la naturaleza humana no tiene otro propósito que el de tocar ciertas fibras íntimas en los seres humanos para poder hacer de ellos un mejor uso instrumental, cabría preguntarse por qué motivo un modo de pensamiento acerca del sentido de la vida humana cercano al aristotélico puede tocar tales fibras en el ser humano occidental hoy día, a fines del siglo XX y principios del XXI. ¿No será esto muestra de que se está gestando un cambio en el pensamiento y en la sensibilidad de nuestra cultura? ¿No habrá implícita aquí una insatisfacción con nuestra condición presente y una añoranza por alcanzar una condición distinta, quizás alguna vez perdida en un pasado remoto? ¿No podría ser el campo de la gerencia un espacio pionero en el cultivo teórico y práctico de esa posible nueva modalidad de pensamiento y de vida?

Resulta difícil dar respuesta a estas preguntas desde la compleja e incierta posición histórica en la que nos encontramos en la actualidad. Quizás haya que esperar a que sea la propia historia la que brinde su respuesta definitiva a estas cuestiones.

\section{Referencias bibliográficas}

Ackoff, Russell (1974), Redesigning the Future. A Systems Approach to Societal Problems, New York, USA, Wiley.

Aristóteles (2000), Nicomachean Ethics, Indianapolis, USA, Hackett Publishing Company.

Bertalanffy, Ludwig Von (1968), General System Theory, London, UK, Penguin.

Checkland, Peter (1981), Systems Thinking, Systems Practice, London, UK, Wiley.

Churchman, Charles (1979), The Systems Approach and Its Enemies, New York, USA, Basic Books.

Foucault, Michel (1966), Las Palabras y las Cosas, Madrid, España, Siglo Veintiuno Editores.

Foucault, Michel (1975), Vigilar y Castigar. Madrid, España, Siglo Veintiuno Editores.

Fuenmayor, Ramsés (1991). Truth and openness: An epistemology for interpretive systemology. Systems Practice, Vol. 4, New York, USA, Plenum Press, pp 473-490.

Fuenmayor, Ramsés (1995), The will to systems. From making sense to Enframing, Critical Issues in Systems Theory and Practice. New York, Plenum Press.

Fuenmayor, Ramsés and López-Garay, Hernán (1991), The scene for interpretive systemology. Systems Practice, Vol. 4, New York, USA, Plenum Press, pp 401-418.

Habermas, Jurgen (1972). Knowledge and Human Interests, London, UK, Heinemann.

Habermas, Jurgen (1973), Theory and Practice, Cambridge, UK, Polity Press. 
Heidegger, Martin (1954), Science and Reflection, The Question Concerning Technology and Other Essays, New York, USA, Harper Torchbooks.

Heidegger, Martin (1955), The Question Concerning Technology, The Question Concerning Technology and Other Essays, New York, USA, Harper Torchbooks.

Hobbes, Thomas (1980), Leviatán, México DF, Fondo de Cultura Económica.

Kant, Immanuel (1987), Ideas para una historia en clave cosmopolita, Madrid, España, Tecnos.
Maclntyre, Alasdair (1985), After Virtue: A Study in Moral Theory, London, UK, Duckworth.

Nietzsche, Friedrich (1998), Sobre verdad y mentira en sentido extramoral, Madrid, España, Tecnos.

Senge, Peter (1993), La Quinta Disciplina. Cómo impulsar el aprendizaje en una Organización Inteligente. Buenos Aires, Argentina, Ediciones Juan Granica.

Taylor, Frederick (1969), Principios de la administración científica, Buenos Aires, Argentina, El Ateneo. 